\title{
RADVAN: a randomised phase 2 trial of WBRT plus vandetanib for melanoma brain metastases - results and lessons learnt
}

\begin{abstract}
Avinash Gupta ${ }^{1}$, Corran Roberts ${ }^{2}$, Finn Tysoe ${ }^{1}$, Matthew Goff ${ }^{3}$, Jenny Nobes ${ }^{4}$, James Lester ${ }^{5}$, Ernie Marshall ${ }^{6}$, Carie Corner ${ }^{7}$, Virginia Wolstenholme ${ }^{8}$, Charles Kelly ${ }^{9}$, Adelyn Wise ${ }^{3}$, Linda Collins ${ }^{3}$, Sharon Love ${ }^{2}$, Martha Woodward ${ }^{1}$, Amanda Salisbury ${ }^{1}$ and Mark R Middleton ${ }^{*}, 1,10$

${ }^{1}$ Department of Oncology, Oxford University Hospitals NHS Foundation Trust, Cancer and Haematology Centre, Churchill Hospital, Old Road, Oxford OX3 7LE, UK; ${ }^{2}$ Centre for Statistics in Medicine, Nuffield Department of Orthopaedics, Rheumatology and Musculoskeletal Sciences, University of Oxford, Botnar Research Centre, Windmill Road, Oxford OX3 7LD, UK; ${ }^{3}$ Oncology Clinical Trials Office, University of Oxford, Old Road Campus Research Building, Roosevelt Drive, Oxford OX3 7DQ, UK; ${ }^{4}$ Norfolk and Norwich University Hospitals NHS Foundation Trust, Colney Lane, Norwich NR4 7UY, UK; ${ }^{5}$ Sheffield Teaching Hospitals NHS Foundation Trust, Weston Park Hospital, Whitham Road, Sheffield S10 2SJ, UK; ${ }^{6}$ Clatterbridge Cancer Centre NHS Foundation Trust, Clatterbridge Road, Wirral CH63 4JY, UK; ${ }^{7}$ Mount Vernon Cancer Centre, Rickmansworth Road, Northwood, Middlesex HA6 2RN, UK; ${ }^{8}$ Barts Health NHS Trust, St. Bartholomew's Hospital, West Smithfield, London EC1A 7BE, UK; ${ }^{9}$ Newcastle upon Tyne Hospitals NHS Foundation Trust, Freeman Hospital, Freeman Road, High Heaton, Newcastle upon Tyne NE7 7DN, UK and ${ }^{10}$ Department of Oncology, NIHR Oxford Biomedical Research Centre, Churchill Hospital, Old Road, Oxford OX3 7LE, UK
\end{abstract}

Background: Brain metastases occur in up to $75 \%$ of patients with advanced melanoma. Most are treated with wholebrain radiotherapy (WBRT), with limited effectiveness. Vandetanib, an inhibitor of vascular endothelial growth factor receptor, epidermal growth factor receptor and rearranged during transfection tyrosine kinases, is a potent radiosensitiser in xenograft models. We compared WBRT with WBRT plus vandetanib in the treatment of patients with melanoma brain metastases.

Methods: In this double-blind, multi-centre, phase 2 trial patients with melanoma brain metastases were randomised to receive WBRT (30 Gy in 10 fractions) plus 3 weeks of concurrent vandetanib $100 \mathrm{mg}$ once daily or placebo. The primary endpoint was progression-free survival in brain (PFS brain). The main study was preceded by a safety run-in phase to confirm tolerability of the combination. A post-hoc analysis and literature review considered barriers to recruiting patients with melanoma brain metastases to clinical trials.

Results: Twenty-four patients were recruited, six to the safety phase and 18 to the randomised phase. The study closed early due to poor recruitment. Median PFS brain was 3.3 months (90\% confidence interval (Cl): 1.6-5.6) in the vandetanib group and 2.5 months (90\% Cl: $0.2-4.8)$ in the placebo group ( $P=0.34)$. Median overall survival $(\mathrm{OS})$ was 4.6 months ( $90 \% \mathrm{Cl}$ : 1.6-6.3) and 2.5 months (90\% Cl: $0.2-7.2)$, respectively $(P=0.54)$. The most frequent adverse events were fatigue, alopecia, confusion and nausea. The most common barrier to study recruitment was availability of alternative treatments.

Conclusions: The combination of WBRT plus vandetanib was well tolerated. Compared with WBRT alone, there was no significant improvement in PFS brain or OS, although we are unable to provide a definitive result due to poor accrual. A review of barriers to trial accrual identified several factors that affect study recruitment in this difficult disease area.

*Correspondence: Professor MR Middleton; E-mail: mark.middleton@oncology.ox.ac.uk

Received 4 May 2016; revised 13 August 2016; accepted 13 September 2016; published online 6 October 2016

(c) 2016 Cancer Research UK. All rights reserved 0007 - 0920/16 
The incidence of melanoma is increasing, both in the UK and worldwide. It is now the fifth most common cancer in the United Kingdom, and second most common cancer in adults aged 25-49 (Cancer Research UK statistics, 2009-2011). Early detection and treatment with surgical excision leads to cure in the majority of cases, but in about $15 \%$ of patients the disease metastasises. In patients with metastatic melanoma, spread to the brain has been reported in up to $75 \%$ of cases, and melanoma is the third most common cancer to metastasise to the brain, after lung and breast cancer (Davies et al, 2011). Median overall survival (OS) in patients diagnosed with melanoma brain metastases is about 4 months, with the brain metastases considered contributing to death in over $90 \%$ of cases (Fife et al, 2004).

Traditionally, most patients have been treated with palliative wholebrain radiotherapy (WBRT), which provides symptomatic benefit, but no significant survival benefit (Davies et al, 2011). Trials of the cytotoxic agents fotemustine and temozolomide, alone or in combination with WBRT, have produced responses in a minority of patients, but again no significant survival benefit (Mornex et al, 2003; Agarwala et al, 2004; Hofmann et al, 2006; Atkins et al, 2008). More recently, in patients with limited tumour burden (generally three or fewer brain lesions), treatment with surgical excision or stereotactic radiosurgery (SRS) has improved survival to 8-9 months (Fife et al, 2004; Davies et al, 2011; Chowdhury et al, 2015). The immunomodulating CTLA-4 inhibitor ipilimumab is effective in some patients with asymptomatic/stable brain metastases (Ajithkumar et al, 2015), whilst the BRAF inhibitors vemurafenib and dabrafenib produce responses in $B R A F$ mutant melanoma patients with symptomatic brain metastases (Long et al, 2012; Dummer et al, 2014). Trials of newer immunomodulating PD-1/PDL-1 inhibitors in patients with brain metastases are ongoing. Nonetheless, the management of melanoma brain metastases, especially for patients with multiple lesions, continues to represent an area of significant unmet medical need, and most trials of new agents exclude patients with active CNS disease.

Vandetanib is an orally bioavailable anti-angiogenic small molecule receptor tyrosine kinase inhibitor that targets vascular endothelial growth factor receptor (VEGFR), epidermal growth factor receptor (EGFR) and rearranged during transfection (RET) tyrosine kinases (Morabito et al, 2009). It has demonstrated anti-tumour activity in melanoma, lung and prostate cancer xenografts (Wedge et al, 2002; Langenkamp et al, 2012), and is licensed for the treatment of medullary thyroid cancer (Bible and Ryder, 2016). In a mouse model of melanoma brain metastases, vandetanib monotherapy demonstrated effective inhibition of angiogenesis but limited effect on tumour growth (Leenders et al, 2004). The effect of vandetanib on tumour vasculature and oxygenation has been found to enhance the efficacy of radiotherapy in lung and head and neck cancer xenografts (Shibuya et al, 2007; Gustafson et al, 2008). Vandetanib $100 \mathrm{mg}$ once daily was found to be the maximum tolerated dose when combined with WBRT and temozolomide in a phase 1 trial of patients with glioblastoma (Drappatz et al, 2010).

The aim of this study was to compare WBRT alone with WBRT plus vandetanib in the treatment of patients with melanoma brain metastases.

\section{MATERIALS AND METHODS}

Study design and patients. This randomised, double-blind, placebocontrolled, multi-centre phase 2 trial (ISRCTN 20253034) was conducted at seven hospitals across the UK under the auspices of the National Cancer Research Institute Melanoma Clinical Study Group. The randomised phase was preceded by a safety run-in phase of six patients who all received WBRT plus vandetanib $100 \mathrm{mg}$ once daily, to confirm tolerability in this patient population. Tolerability was defined as no treatment related toxicity of grade 3 or more (as per NCI CTCAE version 4.03) up to 30 days post end of study treatment in at least 5 out of 6 patients in the safety run-in phase.

Patients were eligible if aged 18 years or older, with advanced melanoma with brain metastases (excluding leptomeningeal disease and ocular malignant melanoma), Karnofsky Performance Score of $70 \%$ or higher, Radiation Therapy Oncology Group (RTOG) recursive partitioning analysis (RPA) score of 1 or 2 (Gaspar et al, 2000), and adequate cardiac, bone marrow, renal, and liver function. All patients needed to have at least one lesion in the brain measurable at study entry as per Response Evaluation Criteria in Solid Tumours (RECIST) version 1.1 (Eisenhauer et al, 2009). Patients were ineligible if they had received any radiotherapy or systemic melanoma therapy within 28 days before starting study treatment. They were also excluded if they had ever received previous WBRT, or if all brain metastases had been previously treated by neurosurgery or SRS. A stipulation of no more than three extra-cranial metastatic sites at screening was removed after the safety run-in phase.

All patients provided written informed consent and the study was conducted in accordance with the UK Clinical Trials Regulations and the ICH guidelines of Good Clinical Practice. The protocol was approved by the independent South Central Hampshire B Research Ethics Committee and by review boards at each study site.

Randomisation and masking. Eligible patients were randomised $1: 1$ to receive WBRT plus vandetanib or WBRT plus placebo, stratifying for RPA score (1 vs 2), using an Interactive Web Response System. Patients and clinicians were kept blinded to the treatment allocation. Vandetanib/placebo was supplied as $100 \mathrm{mg}$ white film-coated tablets packed in high-density polyethylene bottles.

Procedures. Radiotherapy was administered via parallel opposed lateral beams dosed to the midpoint as $30 \mathrm{~Gy}$ in 10 fractions over 2 weeks. Patients in the safety run-in phase all received vandetanib $100 \mathrm{mg}$ once daily, starting 4 days ( \pm 1 day) before WBRT and continuing for 21 days in total. Patients in the randomised phase received vandetanib/placebo as above. If a patient developed significant QT prolongation, or any CTCAE grade 3/4 toxicity considered related to study treatment, vandetanib/placebo was withheld until the toxicity improved to grade 1 or baseline, after which study drug was restarted at a reduced dose of $100 \mathrm{mg}$ once every alternate day. No study drug was given beyond day 21 , even if doses were missed in between.

Endpoints. The primary endpoint was progression-free survival in the brain (PFS brain), assessed by magnetic resonance imaging (MRI) scan using RECIST version 1.1, and defined as time from date of randomisation to date of progression or date of death from any cause, whichever was first. Secondary endpoints included OS, defined as time from date of randomisation to date of death, proportion of patients alive and progression-free in brain at 6 months (APF6), as estimated from the Kaplan-Meier plots, and safety and tolerability. Patients without a PFS or OS event were censored at date of last assessment.

Assessments. Tumour response was based on investigator assessment of brain metastases as per RECIST 1.1, using MRI at baseline, 30 days post treatment, and then at 2 monthly intervals, until 12 months post randomisation or progression in the brain, whichever was first. After this, patients were followed for survival only. Adverse events (AEs) were graded according to NCI CTCAE version 4.03. All patients receiving any study medications were included in the safety analyses.

Statistical analysis. For the randomised phase we originally planned to conduct the primary analysis after recruitment of 80 patients and $\sim 74$ brain progression/death events had occurred. 
Assuming a hazard ratio (HR) of 0.6 (likely to correspond to a $70 \%$ prolongation of PFS brain), this analysis would have $80 \%$ power with a one-sided significance level of 0.01 to demonstrate a statistically significant difference in PFS brain between the two treatment arms. It was estimated that this number of events would occur $\sim 4$ months after the planned 2-year recruitment period. However, due to poor study accrual, recruitment was closed early, meaning that the previously calculated target of 80 patients was not reached. We completed primary and secondary analyses as planned, but adequate evaluation of the benefit of vandetanib in addition to WBRT was not possible due to lack of numbers.

All survival analyses were on an intention-to-treat (ITT) basis, and involved all patients recruited to the randomised phase. Treatment arms were compared for PFS brain and OS using Cox regression analysis. APF6 was compared between treatment groups using the Kaplan-Meier estimates. Analyses were undertaken using Stata version 13.1 (StataCorp, College Station, TX, USA).

Barriers to accrual. Following study closure due to poor accrual we performed a literature review to better understand the factors affecting recruitment to trials of WBRT. We interrogated PubMed using the search terms 'WBRT', 'WBRT + melanoma' and 'WBRT + accrual', limited to clinical trials performed within the last 10 years. Results were hand sorted for relevance by title and abstract. Relevant papers were then mined for additional results by reviewing internal references and registered citations on PubMed. To identify factors specific to the RADVAN study we also circulated a questionnaire to all participating sites, following closure to recruitment, asking what factors investigators thought affected their ability to recruit to RADVAN. Specifically we asked

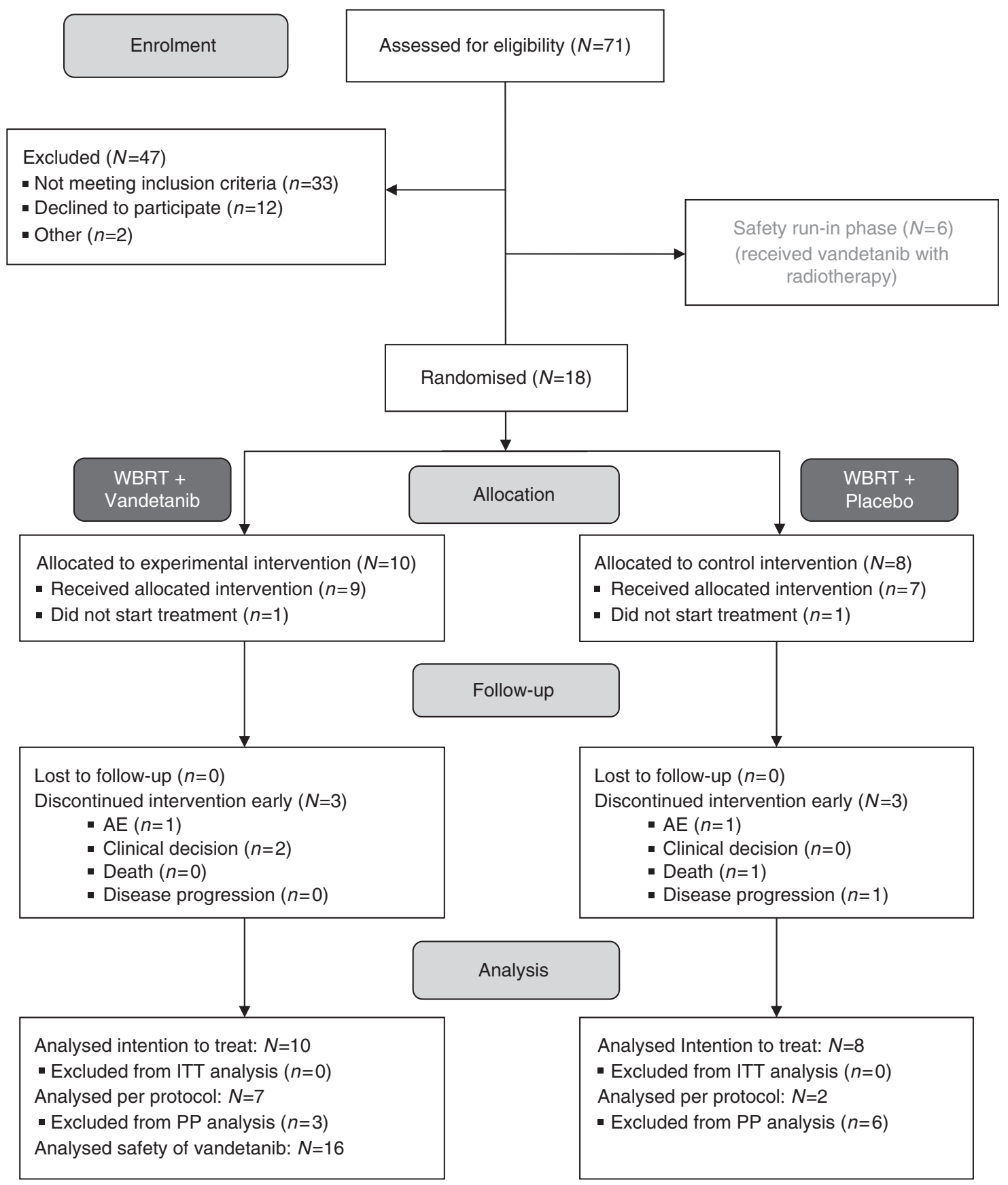

Figure 1. RADVAN study CONSORT flow diagram. 
for the reasons for not screening potentially eligible patients and whether increased use of neurosurgery or SRS and the availability of vemurafenib and ipilimumab affected recruitment.

\section{RESULTS}

Patients. Between December 2011 and April 2014 there were 71 patients screened across seven sites, of which six were recruited to the safety phase (completed February 2013), and 18 were recruited to the randomised phase, which closed in April 2014 due to lack of accrual (Figure 1). The most common reasons for patients failing screening were poor performance status and the choice of alternative treatment $(15 \%$ and $9 \%$ of patients who failed screening respectively). For the randomised phase, 10 patients were allocated to WBRT plus vandetanib and eight to WBRT plus placebo. Baseline characteristics were well balanced between the treatment groups (Table 1).

Safety run-in phase. Six eligible patients were recruited to the safety phase of the trial. One patient did not complete the full course of study drug and was non-evaluable, leaving five evaluable patients. None of these five patients experienced grade 3 or more toxicity considered related to study treatment. Therefore, WBRT 30 Gy in 10 fractions plus vandetanib $100 \mathrm{mg}$ OD for 21 days was considered tolerable and the study proceeded to the randomised phase.

Efficacy. For the randomised phase, the primary endpoint of PFS brain was analysed at the closure of the trial, at which point median follow-up for all patients was 4.5 months. As per ITT analysis, median PFS brain was 3.3 months (90\% confidence interval (CI): 1.6-5.6) in patients randomised to WBRT plus vandetanib and 2.5 months (90\% CI: 0.2-4.8) in patients randomised to WBRT plus placebo (Figure 2A, Table 2). Although lack of numbers precluded accurate assessment of significance, from the data available there was no statistically significant difference in PFS brain between the two treatment groups, with an unadjusted HR of 0.65 (90\% CI: 0.29-1.45; $P=0.34$, Tarone-Ware test). With 17 deaths recorded at analysis, median OS was 4.6 months (90\% CI: 1.6-6.3) in patients randomised to the vandetanib group and 2.5 months (90\% CI: $0.2-7.2)$ in the placebo group, with a HR of 0.85 (90\% CI: $0.37-1.96$; $P=0.54$; Figure $2 \mathrm{~B}$, Table 2). The APF6 was $20 \%$ in the vandetanib group and $13 \%$ in the placebo group (Table 2).

Compliance. For the randomised phase, 7 out of 10 patients $(70 \%)$ in the vandetanib group completed 21 days of study drug compared with 2 out of 8 patients $(25 \%)$ in the placebo group. In the vandetanib group, 8 out of 10 patients completed all 10 days of WBRT compared with 4 out of 8 patients in the placebo group. For the majority of patients not completing WBRT in both treatment arms, the reason was disease progression.

Safety and tolerability. For the safety analysis, all patients who received WBRT plus vandetanib, in both the safety and randomised phases, were included. The most frequent AEs were fatigue, alopecia, confusion and nausea (Table 3 ). Of the total number of AEs, $14 \%$ were CTCAE grades 3 and 4 . In the vandetanib group three patients developed grade 3 confusion, one developed grade 3 QT prolongation and one developed grade 3 constipation. In total 11 serious adverse events (SAEs) occurred; four in the safety run-in phase, five in those randomised to vandetanib and two in those randomised to placebo. The most common SAE was confusion. All deaths were disease related.

Barriers to accrual. The most common reason given by study investigators for not screening potentially eligible patients for this study was preference for alternative treatments. For BRAF mutant melanoma patients with brain metastases, most investigators opted for oral BRAF inhibitor treatment first. For $B R A F$ wild-type melanoma patients with brain metastases, some investigators elected to treat with immunotherapy first, if the brain metastases were small and asymptomatic. Increased use of neurosurgery/SRS, poor prognosis and rapid deterioration were also cited as common reasons for not recruiting patients.

\begin{tabular}{|c|c|c|c|}
\hline Characteristic & WBRT + vandetanib $(N=10)$ & WBRT + placebo $(N=8)$ & Safety cohort $(N=6)$ \\
\hline \multicolumn{4}{|c|}{ Age at randomisation (years) } \\
\hline Mean (min-max) & $57(42-77)$ & $64(44-83)$ & $69(55-77)$ \\
\hline \multicolumn{4}{|l|}{ Gender, n (\%) } \\
\hline $\begin{array}{l}\text { Male } \\
\text { Female }\end{array}$ & $\begin{array}{l}5(50) \\
5(50)\end{array}$ & $\begin{array}{l}3(37.5) \\
5(62.5)\end{array}$ & $\begin{array}{l}4(66.7) \\
2(33.3)\end{array}$ \\
\hline \multicolumn{4}{|c|}{ Karnofsky performance status } \\
\hline $\begin{array}{l}100 \\
90 \\
80 \\
70\end{array}$ & $\begin{array}{l}2(20) \\
5(50) \\
2(20) \\
1(10)\end{array}$ & $\begin{array}{c}1(12.5) \\
5(62.5) \\
2(25) \\
0\end{array}$ & $\begin{array}{c}1(16.7) \\
2(33.3) \\
3(50) \\
0\end{array}$ \\
\hline \multicolumn{4}{|c|}{ Past melanoma treatment, $n(\%)$} \\
\hline $\begin{array}{l}\text { Prior surgery } \\
\text { Prior medical therapy } \\
\text { Prior radiotherapy }\end{array}$ & $\begin{array}{c}10(100) \\
6(60) \\
3(30)\end{array}$ & $\begin{array}{l}7(87.5) \\
6(75) \\
1(12.5)\end{array}$ & $\begin{array}{l}6(100) \\
2(33.3) \\
2(33.3)\end{array}$ \\
\hline \multicolumn{4}{|c|}{ Any extra-cranial metastases, $n(\%)$} \\
\hline $\begin{array}{l}\text { Yes } \\
\text { No }\end{array}$ & $\begin{array}{c}10(100) \\
0\end{array}$ & $\begin{array}{l}7(87.5) \\
1(12.5)\end{array}$ & $\begin{array}{l}5(83.3) \\
1(16.7)\end{array}$ \\
\hline \multicolumn{4}{|c|}{ RTOG RPA score, $n(\%)$} \\
\hline $\begin{array}{l}1 \\
2\end{array}$ & $\begin{array}{c}0 \\
10(100)\end{array}$ & $\begin{array}{c}0 \\
8(100)\end{array}$ & $\begin{array}{l}1 \text { (16.7) } \\
5(83.3)\end{array}$ \\
\hline \multicolumn{4}{|c|}{ Sum of LAD of target lesions in brain } \\
\hline Median (IQR) & $29(16)$ & $31(22.5)$ & $30(25)$ \\
\hline
\end{tabular}


A PFS brain

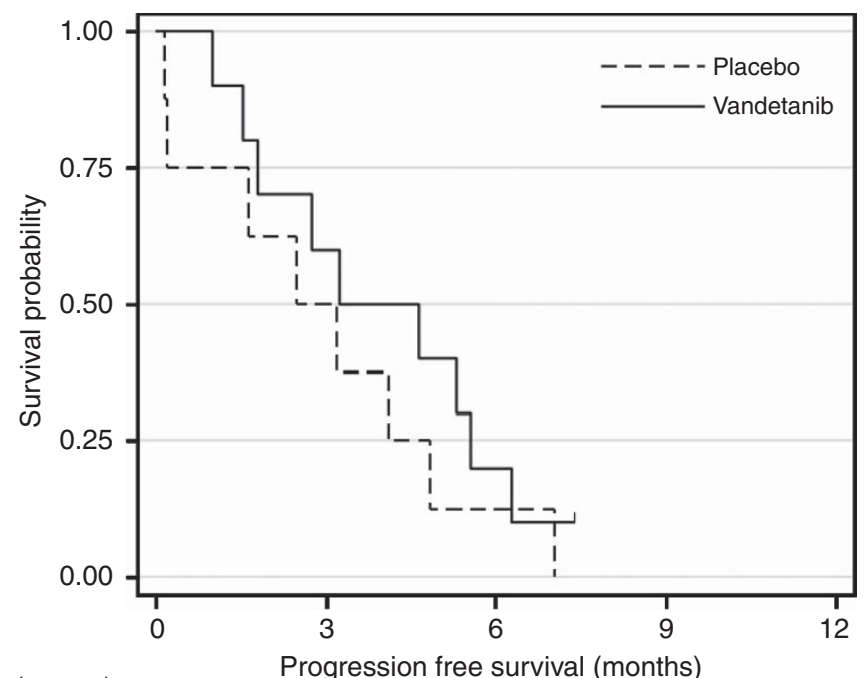

Number at risk (events)

$\begin{array}{llllllllll}\text { Placebo } & 8 & (4) & 4 & (4) & 1 & (0) & 0 & (0) & 0\end{array}$

Vandetanib

10

(4) 6

(4) 2

(1)

(0)

B

Overall survival

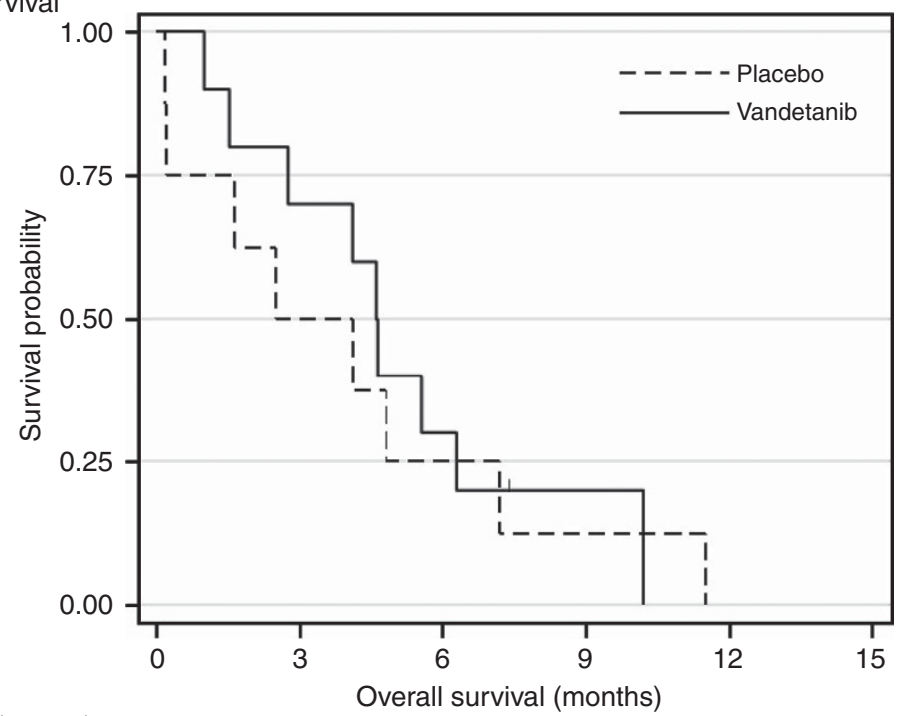

Number at risk (events)

Placebo

Vandetanib

$\begin{array}{ccccc}8 & (4) & 4 & (2) & 2 \\ 10 & (3) & 7 & (4) & 3\end{array}$

(2) 1

(0) 0

(0) 0

Figure 2. Kaplan-Meier curve for (A) PFS brain and (B) OS by treatment group.

Our review of the literature identified seven published studies of WBRT for brain metastases (melanoma or otherwise) in the last 10 years that failed to reach their recruitment target (Roos et al, 2006; Neuhaus et al, 2009; Chua et al, 2010; Hassler et al, 2013; Robins et al, 2013; Sperduto et al, 2013; Niravath et al, 2015). It is reasonable to expect there are more that have not been published. We identified four key themes around failure to recruit:

Reluctance to refer patients for WBRT studies. A number of investigators noted that referring clinicians often have strong anecdotal preferences on whether or not to refer patients with brain metastases for WBRT, based on concerns over WBRTrelated toxicities, and melanoma traditionally being viewed as a radio-resistant disease (Roos et al, 2006; Redmond et al, 2008; Fogarty et al, 2014). With this in mind, Fogarty et al undertook a wide consultation amongst clinicians treating melanoma when setting up their phase 3 trial of WBRT after local treatment of melanoma brain metastases (Fogarty et al, 2011). This helped raise awareness of the proposed study, and identified potential concerns recruiting physicians may have.

For a phase 3 study in patients with non-small-cell lung cancer (NSCLC) brain metastases comparing optimal supportive care (OSC) with OSC plus WBRT, the investigators took a different approach. Slow accrual was thought at least partially due to lack of evidence supporting the hypothesis that OSC alone is non-inferior to OSC plus WBRT, leading to a reluctance to refer patients for the study. So the investigators chose to release interim data, to help inform both patients and clinicians considering study entry (Langley et al, 2013). Following release of the interim data, which supported the study hypothesis, recruitment improved from an average of 6.9 patients per month to 8.8 patients per month (Stephens et al, 2014). 
Availability of alternative treatments. Increased availability of alternative treatments for melanoma brain metastases, namely neurosurgery, SRS, immunotherapy and BRAF inhibitors, has affected recruitment to trials of WBRT, as these alternatives are seen by both patients and clinicians as offering higher chance of benefit and a more appealing side effect profile than WBRT (Ajithkumar et al, 2015). Similar issues have affected accrual to WBRT studies in other tumour types, such as NSCLC (Sperduto et al, 2013; Welsh et al, 2013).

Site selection and overestimation of ability to recruit. Careful selection of study sites with proven ability to recruit within the desired patient population, possession of full on-site treatment facilities and multi-disciplinary clinics, is considered crucial for successful recruitment (Neuhaus et al, 2009; Langley et al, 2013; Fogarty et al, 2014). Central coordination of site set-up and ethics submissions have also been identified as important for successful study accrual (Fogarty et al, 2014).

As part of their phase 3 trial of WBRT after local treatment of melanoma brain metastases, Fogarty et al (2014) undertook a pilot study to assess if accrual to the main study was feasible. Through this they identified that even study sites with proven track records for accrual to melanoma trials often overestimated how many patients they could recruit. The degree of overestimation was less if based on reviewing past records, rather than memory recall. The majority of sites reduced their estimated recruitment figure when asked to sign a research contract that included a prediction of patient recruitment. Despite this, out of 19 sites only 4 succeeded in recruiting to within $50 \%$ of what they had specified in the research contract (Fogarty et al, 2014).

Differences in time to study treatment initiation have been found to vary between sites, with another phase 3 trial of patients with NSCLC brain metastases noting that North American sites on average started treatment more promptly than European/Australian sites, primarily because their patients were randomised more quickly, with $60 \%$ randomised within 2 weeks of diagnosis of brain metastases at North American sites, compared with $32 \%$ at European/Australian sites (Mehta et al, 2009).

The importance of sensitive study design. Many investigators felt sensitive study design, which balanced accrual against both a patient's ability and a site's ability to complete the trial and provide assessable data, is key to encouraging site interest in recruitment as well as patient interest in participation. Study entry criteria in this patient group are generally quite strict, which can limit successful accrual (Neuhaus et al, 2009; Chua et al, 2010; Niravath et al, 2015). In a phase 3 study of WBRT vs WBRT plus thalidomide, a short window between diagnosis of brain metastases and need to start treatment, and a requirement for follow-up with MRI scans every 2 months to assess PFS brain were noted to affect recruitment at some study sites (Knisely et al, 2008). Restrictions on post-protocol treatment can also hinder recruitment, as described in another phase 3 study of NSCLC patients with brain metastases, where the original protocol stipulated further treatment could only be given at time of progressive disease or after 6 months (Sperduto et al, 2013).

\section{DISCUSSION}

The combination of WBRT 30 Gy in 10 fractions plus vandetanib $100 \mathrm{mg}$ once daily is straightforward to administer and well tolerated in patients with melanoma brain metastases. Median PFS brain was increased with the combination, but the low numbers of patients recruited and lack of statistical power to detect differences between treatment arms prevented adequate evaluation of the combination. Data on BRAF mutation status were not collected in this study. However, increasing evidence that BRAF/NRAS status and activation of the PI3K/AKT pathway have a role in the development of melanoma brain metastases means establishing tumour molecular profile will be important in future studies (Chen et al, 2014; Johnson et al, 2015).

Recruitment was expected to take 2 years, but proved more challenging than anticipated. Recruiting six patients to the safety phase alone took 12 months. Even after relaxing entry criteria (by removing the stipulation of no more than three extra-cranial metastatic sites at screening, following feedback from sites that this

\begin{tabular}{|c|c|c|c|c|}
\hline \multirow[b]{2}{*}{$A E$ event } & \multicolumn{2}{|c|}{$\begin{array}{l}\text { WBRT + vandetanib } \\
\text { (including safety cohort) } \\
\qquad N=16\end{array}$} & \multicolumn{2}{|c|}{$\begin{array}{c}\text { WBRT + placebo } \\
N=8\end{array}$} \\
\hline & $\begin{array}{c}\text { All grades } \\
N(\%)\end{array}$ & $\begin{array}{c}\text { Grade } \geqslant 3 \\
N(\%)\end{array}$ & $\begin{array}{c}\text { All grades } \\
N(\%)\end{array}$ & $\begin{array}{c}\text { Grade } \geqslant 3 \\
N(\%)\end{array}$ \\
\hline Fatigue & $6(38)$ & 0 & $4(50)$ & 0 \\
\hline Alopecia & $5(31)$ & 0 & 0 & 0 \\
\hline Confusion & $4(25)$ & $3(19)$ & 0 & 0 \\
\hline Nausea & $4(25)$ & 0 & 0 & 0 \\
\hline Headache & $3(19)$ & 0 & 0 & 0 \\
\hline Constipation & $2(13)$ & $1(6.3)$ & 0 & 0 \\
\hline Rash & $2(13)$ & 0 & $4(50)$ & 0 \\
\hline Cough & $2(13)$ & 0 & $2(25)$ & 0 \\
\hline Diarrhoea & $2(13)$ & 0 & 1 (13) & 0 \\
\hline QT prolongation & $1(6.3)$ & $1(6.3)$ & 0 & 0 \\
\hline Blurred vision & $1(6.3)$ & 0 & 1 (13) & 0 \\
\hline Atrial fibrillation & $1(6.3)$ & 0 & 0 & 0 \\
\hline Pericardial effusion & $1(6.3)$ & 0 & 0 & 0 \\
\hline Other & $9(56)$ & $3(19)$ & $4(50)$ & $4(50)$ \\
\hline
\end{tabular}

\begin{tabular}{|c|c|c|c|}
\hline Parameters & WBRT + vandetanib & WBRT + placebo & One-sided $P$-value \\
\hline \multicolumn{4}{|l|}{ PFS brain (months) } \\
\hline Median $(90 \% \mathrm{Cl})$ & $3.3(1.6-5.6)$ & $2.5(0.2-4.8)$ & 0.339 \\
\hline \multicolumn{4}{|c|}{ Overall survival (months) } \\
\hline Median $(90 \% \mathrm{Cl})$ & $4.6(1.6-6.3)$ & $2.5(0.2-7.2)$ & 0.537 \\
\hline \multicolumn{4}{|c|}{ PFS rate in brain at 6 months } \\
\hline Estimated \% $(90 \% \mathrm{Cl})$ & $20(5-43)$ & $13(1-37)$ & 0.693 \\
\hline
\end{tabular}


had excluded patients who would otherwise have been suitable), only 18 patients were recruited to the randomised phase over a further period of 12 months. Following review by the RADVAN Trial Management Group in April 2014, it was decided that the slow rate of recruitment meant the study would not be able to yield meaningful results within a reasonable timeframe, and so it was closed to further recruitment. This decision was supported by the Independent Early Phase Trials Oversight Committee, AstraZeneca and the national Clinical Trials Awards and Advisory Committee.

The field of melanoma is evolving rapidly, with increasing treatment options available with the potential for activity against melanoma brain metastases as well as extra-cranial disease. The most common reason cited by investigators for not screening potentially eligible patients for the RADVAN study was preference for alternative treatments. Nonetheless, there remain no clear guidelines for management of melanoma brain metastases, with treatment decisions often based on physician and patient preference, rather than robust trial data. In such a rapidly evolving field adaptive clinical trial designs, which can incorporate new treatment strategies based on emerging clinical data, are likely to be key to ensuring successful study recruitment and meaningful outcomes (Zang and Lee, 2014).

A literature review of other studies of WBRT for brain metastases identified a number of other factors that affect study recruitment. Fogarty et al (2011) concluded that international participation is essential to ensure adequate recruitment to trials of melanoma brain metastases. The BREAK-MB study demonstrated how international trials can recruit patients with melanoma brain metastases very successfully, with 172 patients enroled over a 7-month period from 24 centres in six countries (Long et al, 2012). However, several international studies of both melanoma and lung cancer brain metastases have failed, or struggled, to meet their recruitment targets, indicating that this alone is not enough (Chua et al, 2010; Langley et al, 2013; Fogarty et al, 2014). Identifying realistic recruitment targets is important, and the approach taken by Fogarty et al of encouraging sites to provide feasibility forecasts based on reviewing past records, rather than estimating from memory, and including the predicted recruitment number in the research contract, may help (Fogarty et al, 2014). Strategies such as clear and sensitive study design in consultation with clinicians responsible for patient recruitment, along with careful selection of study sites have also helped overcome competition from alternative treatments and bias within the medical community to ensure successful study recruitment.

In summary, recruitment to RADVAN proved more challenging than expected, partly due to increased treatment options available for such patients, and partly because many patients were not fit enough to start study treatment. A number of factors have been identified which affect recruitment to trials of WBRT. These factors need to be carefully considered when designing future clinical trials for this patient population.

\section{ACKNOWLEDGEMENTS}

This work was supported by a collaboration between AstraZeneca and the UK National Cancer Research Network, for which AstraZeneca have provided partial funding. This study was sponsored by the University of Oxford and run by the Oncology Clinical Trials Office (OCTO), Department of Oncology, University of Oxford with statistical input from the Centre for Statistics in Medicine (CSM). MRM is supported by the Oxford NIHR Biomedical Research Centre and Oxford ECMC. Clinical Trial: RADVAN (EudraCT no: 2011-000661-12).

\section{CONFLICT OF INTEREST}

MRM has consulted for and received research funding from AstraZeneca, GlaxoSmithKline and Roche. All other authors have declared no conflicts of interest.

\section{REFERENCES}

Agarwala SS, Kirkwood JM, Gore M, Dreno B, Thatcher N, Czarnetski B, Atkins M, Buzaid A, Skarlos D, Rankin EM (2004) Temozolomide for the treatment of brain metastases associated with metastatic melanoma: a phase II study. J Clin Oncol 22: 2101-2107.

Ajithkumar T, Parkinson C, Fife K, Corrie P, Jefferies S (2015) Evolving treatment options for melanoma brain metastases. Lancet Oncol 16: e486-e497.

Atkins MB, Sosman JA, Agarwala S, Logan T, Clark JI, Ernstoff MS, Lawson D, Dutcher JP, Weiss G, Curti B, Margolin KA (2008) Temozolomide, thalidomide, and whole brain radiation therapy for patients with brain metastasis from metastatic melanoma: a phase II Cytokine Working Group study. Cancer 113: 2139-2145.

Bible KC, Ryder M (2016) Evolving molecularly targeted therapies for advanced-stage thyroid cancers. Nat Rev Clin Oncol 13(7): 403-416.

Chen G, Chakravarti N, Aardalen K, Lazar AJ, Tetzlaff MT, Wubbenhorst B, Kim SB, Kopetz S, Ledoux AA, Gopal YN, Pereira CG, Deng W, Lee JS, Nathanson KL, Aldape KD, Prieto VG, Stuart D, Davies MA (2014) Molecular profiling of patient-matched brain and extracranial melanoma metastases implicates the PI3K pathway as a therapeutic target. Clin Cancer Res 20: 5537-5546.

Chowdhury IH, Ojerholm E, Mcmillan MT, Miller D, Kolker JD, Kurtz G, Dorsey JF, Nagda SN, Geiger GA, Brem S, O'Rourke DM, Zager EL, Gangadhar T, Schuchter L, Lee JY, Alonso-Basanta M (2015) Novel risk scores for survival and intracranial failure in patients treated with radiosurgery alone to melanoma brain metastases. Radiat Oncol 10: 248.

Chua D, Krzakowski M, Chouaid C, Pallotta MG, Martinez JI, Gottfried M, Curran W, Throuvalas N (2010) Whole-brain radiation therapy plus concomitant temozolomide for the treatment of brain metastases from non-small-cell lung cancer: a randomized, open-label phase II study. Clin Lung Cancer 11: 176-181.

Davies MA, Liu P, Mcintyre S, Kim KB, Papadopoulos N, Hwu WJ, Hwu P, Bedikian A (2011) Prognostic factors for survival in melanoma patients with brain metastases. Cancer 117: 1687-1696.

Drappatz J, Norden AD, Wong ET, Doherty LM, Lafrankie DC, Ciampa A, Kesari S, Sceppa C, Gerard M, Phan P, Schiff D, Batchelor TT, Ligon KL, Young G, Muzikansky A, Weiss SE, Wen PY (2010) Phase I study of vandetanib with radiotherapy and temozolomide for newly diagnosed glioblastoma. Int J Radiat Oncol Biol Phys 78: 85-90.

Dummer R, Goldinger SM, Turtschi CP, Eggmann NB, Michielin O, Mitchell L, Veronese L, Hilfiker PR, Felderer L, Rinderknecht JD (2014) Vemurafenib in patients with $\mathrm{BRAF}(\mathrm{V} 600)$ mutation-positive melanoma with symptomatic brain metastases: final results of an open-label pilot study. Eur J Cancer 50: 611-621.

Eisenhauer EA, Therasse P, Bogaerts J, Schwartz LH, Sargent D, Ford R, Dancey J, Arbuck S, Gwyther S, Mooney M, Rubinstein L, Shankar L, Dodd L, Kaplan R, Lacombe D, Verweij J (2009) New response evaluation criteria in solid tumours: revised RECIST guideline (version 1.1). Eur J Cancer 45: 228-247.

Fife KM, Colman MH, Stevens GN, Firth IC, Moon D, Shannon KF, Harman R, Petersen-Schaefer K, Zacest AC, Besser M, Milton GW, McCarthy WH, Thompson JF (2004) Determinants of outcome in melanoma patients with cerebral metastases. J Clin Oncol 22: 1293-1300.

Fogarty G, Morton RL, Vardy J, Nowak AK, Mandel C, Forder PM, Hong A, Hruby G, Burmeister B, Shivalingam B, Dhillon H, Thompson JF (2011) Whole brain radiotherapy after local treatment of brain metastases in melanoma patients-a randomised phase III trial. BMC Cancer 11: 142.

Fogarty GB, Hong A, Jacobsen KD, Reisse CH, Shivalingam B, Burmeister B, Haydu LE, Paton E, Thompson JF (2014) Accrual to a randomised trial of adjuvant whole brain radiotherapy for treatment of melanoma brain metastases is feasible. BMC Res Notes 7: 412.

Gaspar LE, Scott C, Murray K, Curran W (2000) Validation of the RTOG recursive partitioning analysis (RPA) classification for brain metastases. Int J Radiat Oncol Biol Phys 47: 1001-1006. 
Gustafson DL, Frederick B, Merz AL, Raben D (2008) Dose scheduling of the dual VEGFR and EGFR tyrosine kinase inhibitor vandetanib (ZD6474, Zactima) in combination with radiotherapy in EGFR-positive and EGFRnull human head and neck tumor xenografts. Cancer Chemother Pharmacol 61: 179-188.

Hassler MR, Pfeifer W, Knocke-Abulesz TH, Geissler K, Altorjai G, Dieckmann K, Marosi C (2013) Temozolomide added to whole brain radiotherapy in patients with multiple brain metastases of non-small-cell lung cancer: a multicentric Austrian phase II study. Wien Klin Wochenschr 125: $481-486$

Hofmann M, Kiecker F, Wurm R, Schlenger L, Budach V, Sterry W, Trefzer U (2006) Temozolomide with or without radiotherapy in melanoma with unresectable brain metastases. J Neurooncol 76: 59-64.

Johnson DB, Menzies AM, Zimmer L, Eroglu Z, Ye F, Zhao S, Rizos H, Sucker A, Scolyer RA, Gutzmer R, Gogas H, Kefford RF, Thompson JF, Becker JC, Berking C, Egberts F, Loquai C, Goldinger SM, Pupo GM, Hugo W, Kong X, Garraway LA, Sosman JA, Ribas A, Lo RS, Long GV, Schadendorf D (2015) Acquired BRAF inhibitor resistance: a multicenter meta-analysis of the spectrum and frequencies, clinical behaviour, and phenotypic associations of resistance mechanisms. Eur J Cancer 51: 2792-2799.

Knisely JP, Berkey B, Chakravarti A, Yung AW, Curran Jr WJ, Robins HI, Movsas B, Brachman DG, Henderson RH, Mehta MP (2008) A phase III study of conventional radiation therapy plus thalidomide versus conventional radiation therapy for multiple brain metastases (RTOG 0118). Int J Radiat Oncol Biol Phys 71: 79-86.

Langenkamp E, Zwiers PJ, Moorlag HE, Leenders WP, St Croix B, Molema G (2012) Vascular endothelial growth factor receptor 2 inhibition in-vivo affects tumor vasculature in a tumor type-dependent way and downregulates vascular endothelial growth factor receptor 2 protein without a prominent role for miR-296. Anticancer Drugs 23: 161-172.

Langley RE, Stephens RJ, Nankivell M, Pugh C, Moore B, Navani N, Wilson P, Faivre-Finn C, Barton R, Parmar MK, Mulvenna PM. Investigators, Q. (2013) Interim data from the Medical Research Council QUARTZ Trial: does whole brain radiotherapy affect the survival and quality of life of patients with brain metastases from non-small cell lung cancer? Clin Oncol ( $R$ Coll Radiol) 25: e23-e30.

Leenders WP, Kusters B, Verrijp K, Maass C, Wesseling P, Heerschap A, Ruiter D, Ryan A, de Waal R (2004) Antiangiogenic therapy of cerebral melanoma metastases results in sustained tumor progression via vessel co-option. Clin Cancer Res 10: 6222-6230.

Long GV, Trefzer U, Davies MA, Kefford RF, Ascierto PA, Chapman PB, Puzanov I, Hauschild A, Robert C, Algazi A, Mortier L, Tawbi H, Wilhelm T, Zimmer L, Switzky J, Swann S, Martin AM, Guckert M, Goodman V, Streit M, Kirkwood JM, Schadendorf D (2012) Dabrafenib in patients with Val600Glu or Val600Lys BRAF-mutant melanoma metastatic to the brain (BREAK-MB): a multicentre, open-label, phase 2 trial. Lancet Oncol 13: 1087-1095.

Mehta MP, Shapiro WR, Phan SC, Gervais R, Carrie C, Chabot P, Patchell RA, Glantz MJ, Recht L, Langer C, Sur RK, Roa WH, Mahe MA, Fortin A, Nieder C, Meyers CA, Smith JA, Miller RA, Renschler MF (2009) Motexafin gadolinium combined with prompt whole brain radiotherapy prolongs time to neurologic progression in non-small-cell lung cancer patients with brain metastases: results of a phase III trial. Int J Radiat Oncol Biol Phys 73: 1069-1076.

Morabito A, Piccirillo MC, Falasconi F, De Feo G, Del Giudice A, Bryce J, Di Maio M, De Maio E, Normanno N, Perrone F (2009) Vandetanib (ZD6474), a dual inhibitor of vascular endothelial growth factor receptor (VEGFR) and epidermal growth factor receptor (EGFR) tyrosine kinases: current status and future directions. Oncologist 14: 378-390.

Mornex F, Thomas L, Mohr P, Hauschild A, Delaunay MM, Lesimple T, Tilgen W, Bui BN, Guillot B, Ulrich J, Bourdin S, Mousseau M, Cupissol D, Bonneterre ME, de Gislain C, Bensadoun RJ, Clavel M (2003)
A prospective randomized multicentre phase III trial of fotemustine plus whole brain irradiation versus fotemustine alone in cerebral metastases of malignant melanoma. Melanoma Res 13: 97-103.

Neuhaus T, Ko Y, Muller RP, Grabenbauer GG, Hedde JP, Schueller H, Kocher M, Stier S, Fietkau R (2009) A phase III trial of topotecan and whole brain radiation therapy for patients with CNS-metastases due to lung cancer. Br J Cancer 100: 291-297.

Niravath P, Tham YL, Wang T, Rodriguez A, Foreman C, Hilsenbeck SG, Elledge R, Rimawi M (2015) A phase II trial of capecitabine concomitantly with whole-brain radiotherapy followed by capecitabine and sunitinib for brain metastases from breast cancer. Oncologist 20: 13.

Redmond AJ, Diluna ML, Hebert R, Moliterno JA, Desai R, Knisely JP, Chiang VL (2008) Gamma Knife surgery for the treatment of melanoma metastases: the effect of intratumoral hemorrhage on survival. J Neurosurg 109(Suppl): 99-105.

Robins HI, O’Neill A, Mehta M, GRossman S (2013) A phase 3 trial of whole brain radiation therapy and stereotactic radiosurgery alone versus WBRT \& SRS with temozolomide or erlotinib for non-small cell lung cancer and 1 to 3 brain metastases: Radiation n Therapy Oncology Group 0320: in regard to Sperduto et al. Int J Radiat Oncol Biol Phys 86: 809-810.

Roos DE, Wirth A, Burmeister BH, Spry NA, Drummond KJ, Beresford JA, McClure BE (2006) Whole brain irradiation following surgery or radiosurgery for solitary brain metastases: mature results of a prematurely closed randomized Trans-Tasman Radiation Oncology Group trial (TROG 98.05). Radiother Oncol 80: 318-322.

Shibuya K, Komaki R, Shintani T, Itasaka S, Ryan A, Jurgensmeier JM, Milas L, Ang K, Herbst RS, O’Reilly MS (2007) Targeted therapy against VEGFR and EGFR with ZD6474 enhances the therapeutic efficacy of irradiation in an orthotopic model of human non-small-cell lung cancer. Int J Radiat Oncol Biol Phys 69: 1534-1543.

Sperduto PW, Wang M, Robins HI, Schell MC, Werner-Wasik M, Komaki R, Souhami L, Buyyounouski MK, Khuntia D, Demas W, Shah SA, Nedzi LA, Perry G, Suh JH, Mehta MP (2013) A phase 3 trial of whole brain radiation therapy and stereotactic radiosurgery alone versus WBRT and SRS with temozolomide or erlotinib for non-small cell lung cancer and 1 to 3 brain metastases: Radiation Therapy Oncology Group 0320 . Int J Radiat Oncol Biol Phys 85: 1312-1318.

Stephens RJ, Langley RE, Mulvenna P, Nankivell M, Vail A, Parmar MK (2014) Interim results in clinical trials: do we need to keep all interim randomised clinical trial results confidential? Lung Cancer $\mathbf{8 5}$ : $116-118$.

Wedge SR, Ogilvie DJ, Dukes M, Kendrew J, Chester R, Jackson JA, Boffey SJ, Valentine PJ, Curwen JO, Musgrove HL, Graham GA, Hughes GD, Thomas AP, Stokes ES, Curry B, Richmond GH, Wadsworth PF, Bigley AL, Hennequin LF (2002) ZD6474 inhibits vascular endothelial growth factor signaling, angiogenesis, and tumor growth following oral administration. Cancer Res 62: 4645-4655.

Welsh JW, Komaki R, Amini A, Munsell MF, Unger W, Allen PK, Chang JY, Wefel JS, McGovern SL, Garland LL, Chen SS, Holt J, Liao Z, Brown P, Sulman E, Heymach JV, Kim ES, Stea B (2013) Phase II trial of erlotinib plus concurrent whole-brain radiation therapy for patients with brain metastases from non-small-cell lung cancer. J Clin Oncol 31: 895-902.

Zang Y, Lee JJ (2014) Adaptive clinical trial designs in oncology. Chin Clin Oncol 3: 49.

This work is published under the standard license to publish agreement. After 12 months the work will become freely available and the license terms will switch to a Creative Commons AttributionNonCommercial-Share Alike 4.0 Unported License. 